RESEARCH ARTICLE

\title{
Complications and Glycaemic Control of Type 1 Diabetes Mellitus amongst Children Aged 5 to 19 Years Attending Diabetic Clinic at Kamuzu Central Hospital In Malawi
}

\section{Amos Msekandiana ${ }^{1}$, Gladys Chigayo ${ }^{2}$, Sandeni Chiume 3 , Alfred Jaulani ${ }^{4}$, Levina Msuya ${ }^{5}$, Jedeni Bendabenda $^{6}$, Amos Nyaka 7 , Dan Namalika ${ }^{8}$, Geoffrey Manda ${ }^{9}$, Lucy Mungai ${ }^{10}$, Thomas Ngwiri ${ }^{11,12}$, Charles Mwansambo ${ }^{13}$, Joanna Walker ${ }^{14,15}$ and Anjumanara Omar ${ }^{16}$}

${ }^{1}$ Paediatrician and Pediatric Endocrinologist, Kamuzu Central Hospital, Malawi

${ }^{2}$ Clinician Working in Diabetic Clinic, Kamuzu Central Hospital, Malawi

${ }^{3}$ Head of Department, Pediatrics and Child Health, Kamuzu Central Hospital, Malawi

${ }^{4}$ Statistician, Kamuzu Central Hospital, University of North Carolina Project, Malawi

${ }^{5}$ Pediatric Endocrinologist, Kilimanjaro Medical College, Tanzania

${ }^{6}$ Consultant Nutritionist, Malawi WHO, Malawi

${ }^{7}$ Chief Ophthalmologist, Kamuzu Central Hospital, Malawi

${ }^{8}$ Chief Physician and Principal Secretary for Health Malawi Government, Ministry of Health, Malawi

${ }^{9}$ Medical Officer Baylor Oncology Project, Kamuzu Central Hospital, Malawi

${ }^{10}$ Consultant Pediatric Endocrinologist, Head of Department of Pediatric Endocrinology, University of Nairobi, Kenya

${ }^{11}$ Consultant Pediatric Endocrinologist, Gertrudes Hospital, Kenya

${ }^{12}$ Project Manager, Pediatric Endocrinology Training Center for Africa, Kenya

${ }^{13}$ Chief Paediatrician and Chief Advisor, Ministry of Health Malawi Government, Malawi

${ }^{14}$ Consultant Pediatric Endocrinologist, St Marys Hospital, UK

${ }^{15}$ Examiner, Royal College of Paediatrics, UK

${ }^{16}$ Consultant Pediatric Endocrinologist, University of Nairobi, Kenya

*Corresponding author: Amos Msekandiana, Paediatrician and Pediatric Endocrinologist, Kamuzu Central Hospital , Po Box 149, Lilongwe, Malawi, Tel: +2659-9371-0833

\begin{abstract}
Background: Diabetes mellitus type 1 (T1DM) is a disease of public health importance in Africa affecting mostly children and adolescents. Currently, there is insufficiency of impeccable epidemiological data from sub-Saharan Africa on T1DM in children and adolescents.
\end{abstract}

Methods: This was a hospital based cross-sectional study. A total of 41 children and adolescents aged 5 to 19 years with $\geq 6$ months duration of disease and on treatment were enrolled. Standardised questionnaire, medical files and health passport books were used to collect social demographic and clinical information on episodes of severe hypoglycaemia

Citation: Msekandiana A, Chigayo G, Chiume S, Jaulani A, Msuya L, et al. (2020) Complications and Glycaemic Control of Type 1 Diabetes Mellitus amongst Children Aged 5 to 19 Years Attending Diabetic Clinic at Kamuzu Central Hospital In Malawi. Int J Diabetes Clin Res 7:117. doi.org/10.23937/23773634/1410117

Accepted: February 20, 2020: Published: February 22, 2020

Copyright: (c) 2020 Msekandiana A, et al. This is an open-access article distributed under the terms of the Creative Commons Attribution License, which permits unrestricted use, distribution, and reproduction in any medium, provided the original author and source are credited. 
and DKA. Albumin to creatinine ratio was done to screen for microalbuminuria and HBA1C was done to determine glycaemic control. Slit lamp ophthalmoscopy was done to screen for diabetic retinopathy. Chi square test was used to test for associations and $p \leq 0.05$ was considered statistically significant. Spearman's correlation coefficient was used to measure the correlation between complications of T1DM and HBA1c.

Results: In our study the overall proportion of DKA and severe hypoglycaemia was $63.4 \%$ and $56 \%$ respectively. Only $4.88 \%$ had microalbuminuria, none had diabetic retinopathy and $97.56 \%$ had poor glycaemic control. DKA had a statistical significant relationship with mode of insulin storage $\left(\chi^{2}=\right.$ $6.477, p$-value $=0.0039$ ) and there was a positive correlation between DKA and HBA1C.

Conclusion: The proportion of DKA and severe hypoglycemia was high. Additionally, there was a very high proportion of patients with poor glycemic control.

\section{Keywords}

Type 1 diabetes mellitus

\section{Abbreviations}

T1DM: Type 1 Diabetes Mellitus; HBA1c: Glycated Hemoglobin

\section{Introduction}

According to WHO report published on their website on $1^{\text {st }}$ June 2018 , non-communicable diseases have become an issue of global concern with about 41 million deaths per year and 1.6 million deaths occurring as a results of Diabetes alone. In addition, over $85 \%$ of the deaths occur in the low and middle income countries. Thus the aim is to reduce premature deaths from NCDs globally by one third by 2030 [1]. As a matter of fact, Diabetes type 1 (T1DM) is becoming a disease of public health importance in Africa affecting mostly children and teenagers. Currently there is insufficiency of impeccable epidemiological data from sub-Saharan Africa on T1DM in children and adolescents. However, incidence in Tanzania was estimated to be $1.5 / 100,000$, and an increase in incidence in Sudan from 9.5/100,000 in 1991 to $10.3 / 100,000$ in 1995 has been reported [2]. Furthermore, there is no published data seen from Malawi to reflect the burden of T1DM in children and adolescents.

Diabetes type 1 (T1DM) is an autoimmune disease which results from cellular-mediated destruction of the beta cells of the pancreas characterized by deficient insulin production and requires daily administration of insulin [3]. Children with T1DM usually may classically present with symptoms such as polyuria, polydipsia, polyphagia and weight loss. However, in about $19 \%$ of younger children below 5 years parents or guardians may report non-classical symptoms such as nocturnal enuresis, $10.5 \%$ of the under-five may also present with constipation and $25 \%$ of the children inclusively, may present with diabetic ketoacidosis [4]. The latter is a common observation in our clinical practice in Malawi due to delay in diagnosis, misdiagnosis due to lack of knowledge in the subject or even loss of opportunity to diagnose T1DM due to poor health seeking behaviour.

The pathogenesis of T1DM is quite complex with an interplay of genetic, epigenetic, immunologic and environmental factors. As a matter of fact, Type 1 diabetes is mostly present in individuals with no family history. For example, only $10-15 \%$ of the patients have a first- or second-degree relative with the disease. However, the lifetime risk for developing T1DM is significantly increased in relatives of patients, as about $6 \%$ of children, $5 \%$ of siblings and $50 \%$ of monozygotic twins present with the disease compared to $0.4 \%$ prevalence of the general population. Additionally, there are more than 50 T1DM loci which have been identified by genome-wide association studies and meta-analyses [5]. The human leukocyte antigen (HLA) gene located on the major histocompatibility complex (MHC), on chromosome 6 is the main gene which predisposes to T1DM. Furthermore, many other different genetic loci have been found to contribute in a lesser degree to the genetic susceptibility for T1DM alone or in combination with other autoimmune diseases [6].

Environmental factors also play a significant role in aetiology of T1DM. Thus there is strong evidence that is derived from the study of monozygotic twins, where occurrence of the disease in both siblings varies around $50 \%$ and never reaches $100 \%$. The environmental factors involved include viruses (rubella, coxsackievirus B or enteroviruses), toxins and nutrients (cow's milk, cereals). The precise effect of these factors remains unclear, but it is important to be identified, since these factors can be modified and possibly lead to prevention or treatment interventions $[7,8]$.

\section{Study population and design}

This is a cross-sectional hospital based study that was conducted from October 2018 to June 2019. The study was done in the paediatric diabetic clinic at Kamuzu central hospital in Malawi. This is the main referral hospital located in the capital city of Malawi with a paediatric bed capacity of 250 but over 500 children are admitted to the hospital every month. Currently has over 50 children and adolescents with T1DM attending paediatric diabetic clinic. The study included all T1DM children and adolescents aged 5-19 years attending the paediatric diabetic clinic during the study period. Furthermore, those who did not consent to participate in the study or those with comorbid renal conditions such as nephrotic or nephritic syndrome were excluded.

\section{Sampling technique}

All children and adolescents fitting the criteria and coming for health care within the study period were enrolled if consent was granted by their guardians. The 
clinic had over 50 patients by the time of the study and we enrolled 41.

\section{Data collection tools}

Structured questionnaires were used to collect social demographic and clinical information. Additionally, health passport books and medical files were used to ascertain episodes of DKA and severe hypoglycaemia.

\section{Data collection method}

Data on social demographic and clinical information was collected using a precoded structured questionnaire which included the following information: Age, sex, residence, level of education of guardian, insulin regimen used, duration of disease, mode of insulin storage, signs and symptoms leading to diagnosis of T1DM, knowledge on signs and symptoms of hypoglycaemia, blood pressure measurement, BMI, Fasting or random blood glucose plus urine dipstick for ketonuria, quality of injection sites, Tanners stage for puberty. Additionally, Health passport books and medical files were used to ascertain episodes of DKA and severe hypoglycaemia over past 6 months.

\section{Laboratory analysis and procedures}

HBA1c: After cleaning the site with alcohol swab and allowed to dry, the blood sample $(2 \mathrm{ml})$ was obtained and collected using (lavender top) EDTA tubes by venepuncture from all subjects using sterilized disposable $5 \mathrm{ml}$ syringes for HBA1C.The reference measurement procedure has been defined as bN1-deoxyfructosyl-hemoglobin, based on proteolytic digestion of red cell haemoglobin followed by quantitative peptide mapping by HPLC mass spectrometry or HPLC capillary electrophoresis.

Microalbuminuria: 5 to $7 \mathrm{mls}$ of urine was collected using urine collection containers early in the morning before breakfast or any exercise and bring sample immediately after collection for analysis and albumin to creatinine ratio of $\leq 30-300 \mathrm{mg} / \mathrm{g}$ was considered microalbuminuria.

Diabetic retinopathy: Slit lamp ophthalmoscopy was done by an experienced ophthalmologist to diagnose diabetic retinopathy.

\section{Data analysis}

Data was entered and cleaned in excel then exported into SPSS version 23 where data was analyzed. Descriptive statistics was computed for the variables; frequencies and percentages were obtained for categorical variables while for continuous variables, means and respective standard deviations were presented. Chi square test was used to test for associations and $p \leq 0.05$ was considered statistically significant. Spearman's correlation coefficient was used to measure the correlation between complications of T1DM and HBA1c.

\section{Results}

\section{Social demographic and clinical information}

A total of 41 study participants were enrolled in the study. All study participants $(100 \%, n=41)$ had access to the same type of insulin regimen (Insurgen N (NPH) and Insurgen $\mathrm{R}$ (Regular) twice daily dose. Thus they were either on NPH twice daily or regular soluble insulin twice daily. Their ages ranged from 5 years to 19 years with mean age of 12.3 years (STD 2.9). Majority of the patients belonged to age group of $11.5-15.5(60.98 \%, n=$ 25) (Table 1). Mean age at diagnosis was 8.9 years (STD $=3.7)$. Additionally, $53.66 \%(n=22)$ were female and 19 $(46.34 \%)$ were male. Majority of the guardians have had primary education: $(58.54 \%, n=24)$ and were from rural background $(60.98 \%, n=25$ ) (Table 1 ).

The mean duration of diagnosis of T1DM was 3.2 years ( $S D=2.6)$. The study participants had been diagnosed with T1DM between the periods of 6 months and 10 years prior to the study with a majority belonging to the period between 1.1 years to 3 years $(36.59 \%, n=$ 15). Additionally, $19.51 \%(n=8)$ had duration of disease of 5 years (Table 1 ). Family history of DM was elicited in

Table 1: Social demographic and clinical characteristics.

\begin{tabular}{|c|c|c|}
\hline Variable & Frequency $(N=41)$ & $\begin{array}{l}\text { Percentage } \\
(100)\end{array}$ \\
\hline \multicolumn{3}{|l|}{ Age group } \\
\hline $5-11.5$ years & 13 & 31.7 \\
\hline $11.5-15.5$ years & 25 & 60.98 \\
\hline $15.9-19$ years & 3 & 7.32 \\
\hline \multicolumn{3}{|l|}{ Sex } \\
\hline Female & 22 & 53.66 \\
\hline Male & 19 & 46.34 \\
\hline \multicolumn{3}{|l|}{ Residence } \\
\hline Urban & 25 & 60.98 \\
\hline Rural & 16 & 39.02 \\
\hline \multicolumn{3}{|c|}{ Caretaker Education } \\
\hline Primary & 24 & 58.54 \\
\hline Secondary & 16 & 39.02 \\
\hline Tertiary & 1 & 2.44 \\
\hline \multicolumn{3}{|l|}{ Missed Tx } \\
\hline Yes & 8 & 19.51 \\
\hline No & 33 & 80.49 \\
\hline \multicolumn{3}{|l|}{$\begin{array}{l}\text { Mode of Insulin } \\
\text { Storage }\end{array}$} \\
\hline Traditional & 31 & 75.61 \\
\hline Fridge & 10 & 24.39 \\
\hline \multicolumn{3}{|c|}{ Duration of disease } \\
\hline$<1$ Year & 4 & 9.76 \\
\hline 1-3 Years & 24 & 58.54 \\
\hline 4-5 Years & 5 & 12.2 \\
\hline$>5$ Years & 8 & 19.51 \\
\hline
\end{tabular}




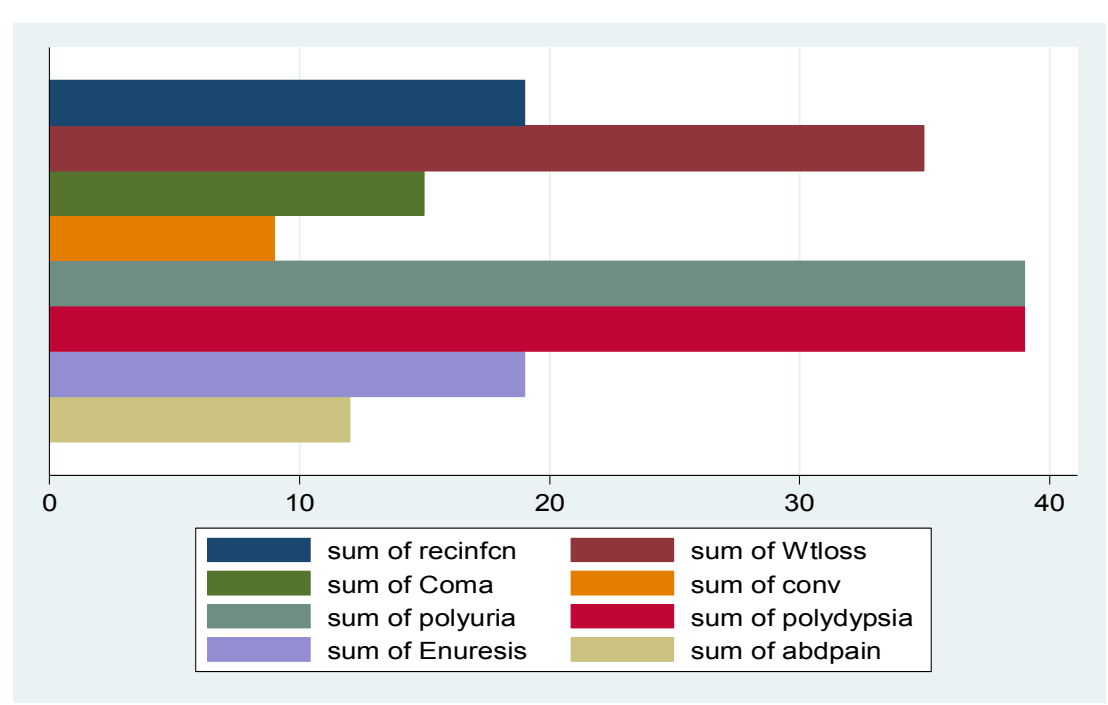

Figure 1: Signs and symptoms that led to diagnosis of T1DM among patients.

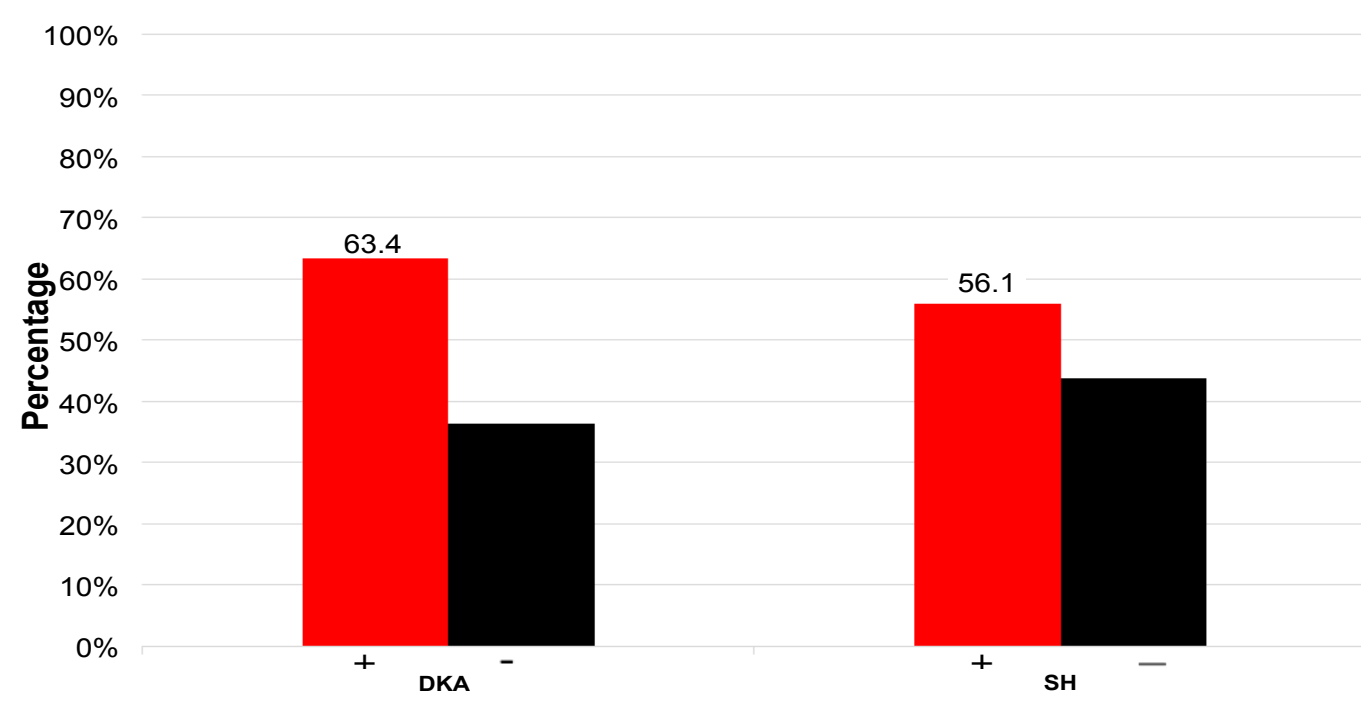

Figure 2: Proportion of acute complications among patients with T1DM.

$24.39 \%(n=10)$ of the cases. The commonest means of storage of insulin was traditional methods (storing insulin in a clay pot with sand and water) in $75.61 \%(n=31)$ of the cases (Table 1). Good compliance to insulin administration as defined by having a participant not missing a dose in the past three months before the interview was reported in $80.49 \%(n=33)$ of the cases. Inspection of the injection sites showed that $82.93 \%(n=34)$ had good injection sites. Additionally, the mean body mass index of the participants was 17.35 kilogram per meter squared (STD $=2.56$ ). Tanners staging for pubertal assessment was done and majority of the patients were Tanners stage $1(53.66 \%, n=22)$.

The symptoms that led to the diagnosis of T1DM included: Recurrent infections in $46.34 \%(n=19)$, weight loss in $85.37 \%(n=35)$, coma in $36.59 \%(n=15)$, convulsions in $21.95 \%(n=9)$, polyuria in $95.12 \%(n=39)$, polydipsia in $95.12 \%(n=39)$, enuresis in $46.34 \%(n=19)$ and abdominal pain in $29.27 \%(n=12)$ (Figure 1$)$.

\section{Proportion of acute complications}

The overall proportion of severe hypoglycaemia (SH) was $56.10 \%(n=23)$. The following were reported as $\mathrm{SH}$ events that were relieved by eating a sugar containing food among the participants that had SH $(n=23)$ : hunger $(82.61 \%, n=19)$, tremors $(52.17 \%, n=12)$, tingling around the mouth $(39.13 \%, \mathrm{n}=9)$, anxiety $(26.09 \%$, $n=6)$, weakness $(86.96 \%, n=20)$, headache $(69.57 \%$ $\mathrm{n}=16)$, slurred speech $(43.48 \% \mathrm{n}=10)$, and dizziness $(34.78 \%, n=8)$. The overall proportion of diabetic ketoacidosis DKA was $63.41 \%(n=26)$ (Figure 2$)$.

\section{Glycaemic control and chronic complications among study participants}

Among the patients studied, 97.56\% ( $n=40)$ had poor glycaemic control with their mean $\mathrm{HbA} 1 \mathrm{c}$ level of 13.22 (STD = 2.4). The proportion of microalbuminuria was $4.88 \%(n=2)$ and $0 \%$ had diabetic retinopathy. 
Table 2: Association between DKA with social demographic and clinical characteristics.

\begin{tabular}{|c|c|c|c|c|}
\hline \multicolumn{5}{|c|}{ DKA } \\
\hline & Total & No & Yes & $\mathrm{X}^{2}, \mathrm{p}$-value \\
\hline Age & & & & $11.896,0.539$ \\
\hline 5-11.5 Years & 13 & 4 & 9 & \\
\hline 11.5-15.5 Years & 25 & 11 & 14 & \\
\hline 15.5-19 Years & 3 & 0 & 3 & \\
\hline Sex & & & & $0.001,0.975$ \\
\hline Female & 22 & 14 & 8 & \\
\hline Male & 19 & 12 & 7 & \\
\hline Residence & & & & $38.845,0.223$ \\
\hline Urban & 17 & 11 & 6 & \\
\hline Rural & 24 & 4 & 20 & \\
\hline Education & & & & $8.453,0.489$ \\
\hline Primary & 24 & 8 & 16 & \\
\hline Secondary & 16 & 7 & 9 & \\
\hline Tertiary & 1 & 0 & 1 & \\
\hline Duration of Disease & & & & $21.912,0.11$ \\
\hline$<1$ Year & 4 & 1 & 3 & \\
\hline 1-3 Years & 24 & 11 & 13 & \\
\hline 3-5 Years & 5 & 0 & 5 & \\
\hline$>5$ Years & 8 & 3 & 5 & \\
\hline Mode of Insulin Storage & & & & $6.477,0.039$ \\
\hline Traditional & 31 & 8 & 23 & \\
\hline Fridge & 10 & 7 & 3 & \\
\hline
\end{tabular}

\section{Association between complications of T1DM with social demographic, and clinical characteristics}

There was statistical significant relationship between DKA and mode of insulin storage $\left(\chi^{2}=6.477\right.$, $p$-value $=0.0039)$ but there was no statically significant relationship between DKA with age, sex, residence, guardian education, missed treatment and duration of disease. Additionally, there was no statistical significant relationship between $\mathrm{SH}$, microalbuminuria with social demographic or clinical characteristics respectively (Table 2, Table 3 and Table 4).

\section{Discussion}

In our study the mean age of diagnosis for T1DM was 12.3years $(S D=2.9)$ and mean duration of disease was 3.2 years $(S D=2.4)$. The overall proportion of patients who had diabetic ketoacidosis (DKA) and severe hypoglycaemia (SH) was $63.4 \%$ and $56 \%$ respectively. Additionally, only $4.88 \%$ had microalbuminuria and none had diabetic retinopathy. Furthermore, $97.56 \%$ had poor glycaemic control and the mean HBA1C was $13.22(S D=3.4)$. DKA had a statistical significant relationship with mode of insulin storage $\left(\chi^{2}\right.$ $=6.477, \mathrm{p}$-value $=0.0039$ ) and there was a positive correlation between DKA and HBA1c.

This is the first study done on the topic in Malawi and no similar studies published according to our knowledge. Our study is similar to Majaliwa, et al. [2], a survey done at Muhimbili national hospital in Tan-

Table 3: Association between severe hypoglycemia with social demographic and clinical characteristics.

SH

\begin{tabular}{|c|c|c|c|c|}
\hline & ..Total & .........No & ...Yes & $X^{2}, p$-value \\
\hline Age & & & & $12.974,0.45$ \\
\hline 5-11.5 Years & 13 & 6 & 7 & \\
\hline 11.5-15.5 Years & 25 & 10 & 15 & \\
\hline 15.5-19 Years & 3 & 3 & 0 & \\
\hline Sex & & & & $0.173,0.678$ \\
\hline Female & 22 & 9 & 13 & \\
\hline Male & 19 & 9 & 10 & \\
\hline Residence & & & & $33.556,0.44$ \\
\hline Urban & 17 & 10 & 7 & \\
\hline Rural & 24 & 8 & 16 & \\
\hline Education & & & & $9.492,0.393$ \\
\hline Primary & 24 & 10 & 14 & \\
\hline Secondary & 16 & 7 & 9 & \\
\hline Tertiary & 1 & 1 & 0 & \\
\hline Duration of Disease & & & & $12.497,0.641$ \\
\hline$<1$ Year & 4 & 2 & 2 & \\
\hline 1-3 Years & 24 & 11 & 13 & \\
\hline
\end{tabular}




\begin{tabular}{|l|l|l|l|l|}
\hline 3-5 Years & 5 & 2 & 3 & \\
\hline > 5 Years & 8 & 3 & 5 & $0.150,0.698$ \\
\hline Missed Tx & 41 & 33 & 8 & $2.156,0.34$ \\
\hline Mode of Insulin Storage & & & & \\
\hline Traditional & 31 & 12 & 19 & \\
\hline Fridge & 10 & 6 & 4 & \\
\hline
\end{tabular}

Table 4: Association between microalbuminuria with social demographic and clinical characteristics.

\begin{tabular}{|c|c|c|c|c|}
\hline \multicolumn{5}{|l|}{ MICROALBUMINURIA } \\
\hline & Total & No & Yes & $x^{2}, p$-value \\
\hline Age & & & & $10.212,0.676$ \\
\hline 5-11.5 Years & 13 & 13 & 0 & \\
\hline 11.5-15.5 Years & 25 & 23 & 2 & \\
\hline 15.5-19 Years & 3 & 3 & 0 & \\
\hline Sex & & & & $0.110,0.915$ \\
\hline Female & 22 & 21 & 1 & \\
\hline Male & 19 & 18 & 1 & \\
\hline Residence & & & & $30.224,0.606$ \\
\hline Urban & 17 & 16 & 1 & \\
\hline Rural & 24 & 23 & 1 & \\
\hline Education & & & & $2.935,0.967$ \\
\hline Primary & 24 & 23 & 1 & \\
\hline Secondary & 16 & 15 & 1 & \\
\hline Tertiary & 1 & 1 & 0 & \\
\hline Duration of Disease & & & & $24.837,0.052$ \\
\hline$<1$ Year & 4 & 4 & 0 & \\
\hline 1-3 Years & 24 & 23 & 1 & \\
\hline 3-5 Years & 5 & 5 & 0 & \\
\hline$>5$ Years & 8 & 7 & 1 & \\
\hline Mode of Insulin Storage & & & & $1.079,0.583$ \\
\hline Traditional & 31 & 29 & 2 & \\
\hline Fridge & 10 & 10 & 0 & \\
\hline
\end{tabular}

zania before establishment of a diabetic center which is currently the case in Malawi. Thus the proportion of children with DKA was equally above $60 \%$. Additionally, $55.6 \%$ of the children had had at least an episode of $\mathrm{SH}$ which is similar to our result whereby we found the proportion of SH to be $56 \%$ [2]. Similarly, a study done by Elamin, et al. [9] at the university hospital of Khartoum in Sudan, this was in the early period before full establishment of their centers of endocrinology and diabetes; the prevalence of DKA was high (81.2\%) [9]. Thus in a review on diabetes in Africa by Lugheti L and Majaliwa ED, et al. [10] they concluded that the prevalence DKA amongst already diagnosed T1DM was between $25-90 \%$ which is high. Additionally, in the review the conclusion for the observed increased prevalence of DKA in Africa was that there is lack of awareness among health workers and community at large which is the case with Malawi [10]. The whole Malawi as a nation has no diabetic center let alone has no pediatric endocrinologist nor trained clinicians and diabetic nurses.

Furthermore, in the same review by Lugheti $L$, and Majaliwa ED, [10], they had observed that the prevalence of SH was equally high ranging between $25-55 \%$ [10]. It was concluded that the most likely factor contributing to this result was due to lack of blood glucose monitoring at individual or hospital level which is the case in Malawi according to observations whereby there is lack of blood glucose monitoring due to unavailability of glucometers or glucostix. Hence the higher proportion of $\mathrm{SH}$ (56\%). As a matter of fact, almost all our patients with $\mathrm{SH}$ in this study, were diagnosed after visiting the emergency department or outpatient department with neuroglycopenic symptoms of hypoglycemia.

In contrast to our study, a study done by Birkebaek, NH, et al. [11] in Nordic countries (Denmark, Ireland, Norway and Sweden) showed a lower overall 
prevalence of $\mathrm{SH}$ at $10.4 \%$ and the main reason is that most patients had adopted new technology in terms insulin administration such as use of pumps and sensors plus a rigorous blood glucose monitoring. Additionally, increased literacy rates amongst guardians could also be a contributing factor since they would understand how to do carbohydrate counting thus corresponding amount of insulin administered to amount of carbohydrate given [11]. Furthermore, in a systematic review done in 31 countries on variation in the frequency of DKA in T1DM by Usher-smith, et al. [12], it was observed that the countries with the lowest frequency of DKA were Sweden 14\%, Canada $18.6 \%$, Finland $22 \%$ and Hungary $23 \%$ which in comparison to our study they had very low frequencies of DKA. As a matter of fact, they observed that countries with higher gross domestic product (GDP) and with higher incidence of type 1 diabetes had lower frequencies of DKA. Thus it was concluded that these countries have increased awareness and hence earlier detection DKA. Additionally, due to their increased GDP their social economic status is higher and they provide a better health care provision than countries like Malawi where our study was done [12].

In terms of chronic complications of T1DM, we had only $4.88 \%$ with microalbuminuria and none had retinopathy. This observation could be explained by the fact that our sample size was small and we had a mean duration of disease of 3.2 years (STD $=2.4$ ) with $53.66 \%$ in Tanners stage 1 . According to international society of pediatric and adolescent diabetes (ISPAD guidelines 2018), the risk of developing microalbuminuria and retinopathy is higher at 11 years when the children enter puberty with mean duration of T1DM of 5 years [13]. Furthermore, in a study done by Razavi in 2009 in Iran on frequency of microalbuminuria; he found $14.5 \%$ frequency of microalbuminuria among children with T1DM and the mean age was 16.2 years (standard deviation = 2.8) and mean duration pf T1DM was 4.5 years (STD = 3.9) which was higher compared to our study [14].

The study result showed a very high proportion of poorly controlled T1DM patients. Thus we had a proportion of $97.56 \%$ with poorly controlled T1DM and the mean HBA1c was $13.22 \%$ (STD = 2.4). Similarly, Ngwiri did a study on glycemic control in Kenyan children and adolescents with T1DM, he found out that $72 \%$ were poorly controlled with median HBA 1c of $11.1 \%$. Additionally, he attributed such a higher proportion to less aggressive management and poor follow up of T1DM patients which is the case in our setting where the study was done [15]. In a study done in Ethiopia in 2016, they found more than $50 \%$ poorly controlled children with T1DM.The reasons for this result were; shortage of resources, low awareness of practicing professionals or failure to follow guidelines in management of T1DM which is the case with the Malawi setting [16]. However, in a study done in Nordic countries, the mean HBA1c range was 6.7 to $8.1 \%$ which was good T1DM control compared to our study with mean HBA1c of $13.2 \%$ [11]. This observation provides evidence that the social economic status plays a crucial role in health care system delivery amongst other factors such as political will.

Furthermore, in our study we observed that there was a statistical significant relationship between mode of insulin storage and DKA and we haven't found similar studies on the topic to compare or contrast. About $75.6 \%$ of our study subjects use traditional method of insulin storage i.e. a clay pot with sand and water kept at the coolest place in their house. Additionally, we also observed a positive correlation between DKA and HBA1c. This result is similar to a study done by Ekpebegh in South Africa whereby they observed that DKA had a significantly positive correlation with HBA1c [17]. Thus if we can achieve normoglycemic states in our patients with good management and monitoring of diabetes we are likely to reduce the HBA1c to desirable levels consequently maintaining a good glycaemic control and reducing prevalence of both acute and chronic complications.

In general, the survey addressed crucial issues on overall performance in terms of how our T1DM patients have been managed over the years and in this case provides a clear direction on way forward and what can be done differently in our clinics. As a matter of fact, treatment for all patients was changed to at least $2 \times \mathrm{NPH}+$ $3 \times$ boluses of soluble insulin with intensified protocols for screening of complications and HBA1c monitoring. In addition, the study generates a clear hypothesis for future studies and may provide an opportunity for training and research amongst colleagues and other cadres who have interest in diabetes. In terms of limitations, this was a hospital based study and our sample size was smaller compared to other studies.

\section{Conclusion}

Conclusively, in our study we found robust evidence on presence of acute complications of T1DM amongst our patients and we also observed that almost all patients had poorly controlled T1DM. Additionally, with higher proportions of DKA and SH observed in this study there is a possibility that many children with T1DM have died at home even during their sleep. Therefore, we recommend training on management of T1DM amongst our clinicians, nurses, psychologists and nutritionists which will also translate into good diabetic education and improved home management of T1DM for our patients.

Furthermore, screening for acute, chronic complications and HBA1c monitoring is mandatory in all children and adolescents with T1DM. Therefore, clinicians and nurses should be trained on management of T1DM and it should be emphasized that diabetic education is the cornerstone in management of T1DM. Additionally, Awareness campaigns must be done to alert peo- 
ple on signs and symptoms as well as complications of T1DM to foster early diagnosis and detection of complications thereby reducing extent of morbidity and mortality. Otherwise prevention of complications of T1DM is more cost effective than treatment.

\section{Ethical Clearance}

Ethical clearance was obtained from Malawi national commission for science and technology study protocol number: 18/11/2184 and signed informed consent were obtained from parents/legal guardians of children before enrolled in the study. The signed consents were kept in a secure place and accessed only by principal investigator.

\section{Declarations}

- Ethical Approval and Consent: The study was approved by NHSRC ethics committee and the guardians of the children signed a consent form to grant permission for the researcher to proceed with data collection.

- Consent for Publication: Guardians filled consent form while collecting data and there are no pictures or videos.

- Data material can be provided upon request by publisher.

- There are no competing interests.

- Authors Contribution: AM is the one who developed proposal, collected and analyzed data and developed the manuscript, GC, SC, AJ, LM, JB, AN, $D N, L M, T N, C M, J W$ and $A A$ : These were major contributors in development of proposal, they reviewed the topic, offered advice on how it could be modified to address the intended goal, they all looked at the feasibility of analytical methods and help intellectual understanding and editing of the manuscript., CM, JW, AA are also supervisors for this study since it was also part of the first authors thesis for fellowship in pediatric endocrinology while training under European society of pediatric endocrinology(ESPE) at the Pediatric endocrinology training center for Africa (PETCA) in Kenya, Nairobi.

- Acknowledgements: This research was funded by International Society of Pediatric and Adolescent Diabetes (ISPAD).

- First Authors Information: Dr. Amos Msekandiana is a consultant pediatrician and pediatric endocrinologist (ESPE) working at Kamuzu central hospital under Ministry of health, Malawi government, in Lilongwe, Malawi.

\section{References}

1. https://www.who.int/ncds/governance

2. Majaliwa ES, Munubhi E, Ramaiya K, Mpembeni $R$,
Sanyiwa A, et al. (2007) Survey on acute and chronic complications in children and adolescents with type 1 diabetes at Muhimbili National Hospital in Dar es Salaam, Tanzania. Diabetes Care 30: 2187-2192.

3. Harrison LC, Honeyman MC, Morahan G, Wentworth JM, Elkassaby S, et al. (2008) Type 1 diabetes: Lessons for other autoimmune diseases? J Autoimmun 31: 306-310.

4. Roche EF, Menon A, Gill D, Hoey H (2005) Clinical presentation of type 1 diabetes. Pediatr Diabetes 6: 75-78.

5. Paschou SA, Marketou NP, Chrousos GP, Gantenbein CK (2018) On type 1 diabetes mellitus pathogenesis. Endocr Connect 7: R38-R46.

6. Størling J, Pociot F (2017) Type 1 diabetes candidate genes linked to pancreatic islet cell inflammation and beta-cell apoptosis. Genes 8: E72.

7. Beyan H, Riese H, Hawa MI, Beretta G, Davidson HW, et al. (2012) Glycotoxin and autoantibodies are additive environmentally determined predictors of type 1 diabetes. Diabetes 61: 1192-1198.

8. Redondo MJ, Rewers M, Yu L, Garg S, Pilcher CC, et al. (1999) Genetic determination of islet cell autoimmunity in monozygotic twin, dizygotic twin, and non-twin siblings of patients with type 1 diabetes: Prospective twin study. BMJ 318: 698-702.

9. Elamin A, Altahir H, Ismail B, Tuvemo T (1992) Clinical pattern of childhood type 1 (insulin-dependent) diabetes mellitus in the Sudan. Diabetologia 35: 645-648.

10. Majaliwa ES, Elusiyan BE, Adesiyun OO, Laigong P, Adeniran AK, et al. (2008) Type 1 diabetes mellitus in the African population: Epidemiology and management challenges. Acta Biomed 79: 255-259.

11. Birkebaek NH, Drivvoll AK, Ackeson K, Bjarnason R, Johansen $A$, et al. (2017) Incidence of severe hypoglycemia in children with type 1 diabetes in the Nordic countries in the period 2008-2012: Association with haemoglobin A1c and treatment modality. BMJ Open Diab Res Care 5: e000377.

12. Usher-Smith JA, Thompson M, Ercole A, Walter FM (2012) Variation between countries in the frequency of diabetic ketoacidosis at first presentation of type 1 diabetes in children: A systematic review. Diabetologia 55: 2878-2894.

13. ISPAD clinical practice consensus guidelines 2018.

14. Razavi Z, Momtaz HE, Sahari S (2009) Frequency of microalbuminuria in type 1 diabetic children. Iran J Pediatr 19: 404-408.

15. Ngwiri T, Were F, Predieri B, Ngugi $P$, Lorenzo lughetti (2015) Glycaemic control in Kenyan children and adolescents with type 1 diabetes mellitus. International Journal of Endocrinology.

16. Shibeshi MS, Fantahun B, Kebede T, Tilahun B (2016) Paediatric diabetic retinopathy: Experience of a tertiary hospital in Ethiopia. BMC Res Notes 9: 116.

17. Ekpebegh CO, Longo-Mbeza B, Blanco-Blanco E (2014) Glycosylated haemoglobin is markedly elevated in new and known diabetes patients with hyperglycaemic ketoacidosis. Afr Health Sci 14: 526-532. 